
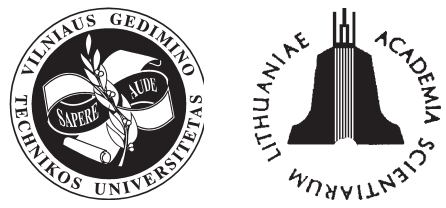

ISSN 1648-4142 print / ISSN 1648-3480 online TRANSPORT

www.transport.vtu.lt

\title{
EFFICIENCY OF A BRAKING PROCESS EVALUATING THE ROUGHNESS OF ROAD SURFACE
}

\author{
Marijonas Bogdevičius ${ }^{1}$, Oleg Vladimirov ${ }^{2}$ \\ Dept of Transport Technological Equipment, Vilnius Gediminas Technical University, \\ Plytinès g. 27, LT-10105 Vilnius, Lithuania. Phone: (+370 5) 2744782 \\ E-mail:1'marius@ti.vtu.lt, ${ }^{2}$ oleg@eltalis.lt
}

Received 12 December 2005; accepted 26 January 2006

\begin{abstract}
Transport traffic safety depends on many factors; one of them being the efficiency of the vehicle braking. The efficiency of the vehicle depends on the reaction of the driver, the braking system, the quality of tires, the characteristics of the road surface. The vehicle with the hydraulic braking system and a disc brake with the wheel has been investigated. The dynamic models of the disk brake assembly and the wheel have been constructed. The braking distances of the vehicle with a hydraulic ABS on the asphalt concrete pavement with shortwave roughness and different initial velocity are obtained.
\end{abstract}

Keywords: dynamics, vehicle, hydraulic braking system, ABS, tire, roughness, numerical method

\section{Introduction}

The study of the effects of asphalt surface roughness on vehicle responses has been interesting to researchers. The solution of this problem can be interesting and useful to increase traffic safety. Dynamic tire forces are thought to be a cause of increased roughness and damage to roads caused by vehicles. It is noticed that roughness of road surface often changes and increases just in the places where vehicles are often braked. This process proceeds faster when the temperature of road surface is high.

To investigate the braking process three important aspects should be addressed. First, the interaction between uneven road surface and the vehicle needs to be carefully taken into account. The effect of the vehicle loading on the road surface, referred to as the interaction force, can be influenced significantly by the dynamic interaction between road and tires of the vehicle, which results in inefficient work of ABS. Second, good representation of road surface roughness is necessary. Road surface roughness is a random process. Finally, the dynamic model of the vehicle should be as realistic as possible.

The purpose of the article is to show the dependence of braking distance on the roughness of surface road when the transport device has ABS.

We apply a Monte Carlo simulation technique to generate a stochastic process of road surface rough- ness. A three dimensional model of the behavior of the vehicle with a hydraulic brake system and ABS is used.

Among many points of view and research stages in the field of the automobile dynamics development we are studying fundamental subjects by focusing on the improvement of automobile dynamic behaviour. Considering the importance of braking processes, we are studying suspensions, hydraulic brake systems, parameters of tires and characteristics of the road. Although automobile behaviour during braking has been studied by many authors, most of the investigations have dealt simple dynamic models evaluating only suspension and automobile inertia characteristics. The analysis of the influence of drivers' reaction, a hydraulic brake system of the automobile, interaction of tires with the surface has rarely been reported.

The modern automotive braking system was refined for over 100 years and now is extremely dependable and efficient. A typical disc braking system consists of a disc (rotor), a caliper housing, a piston, a seal and pads.

When braking, the system generates fluid pressure that pushes the piston towards the shoe with lining, forcing the shoe with lining to rub against the disk and generating the braking torque to stop the vehicle. When studying the dynamics of the automobile braking process, an impact of the most important parameters of the braking system on the breaking process 
shall be taken into consideration [1-3]. The following parameters of the braking system may be considered as the most important: hydraulic system, brake fuel physical characteristics, caliper housing, elastic and damping characteristics of braking pads, initial distance and coefficient of friction between the pad and the disc, characteristics of the vehicle suspension, interaction between the wheel and the road surface. This article deals with the automobile three dimensional model with a hydraulic braking system, suspension as well as dynamic processes of interaction between the wheel and the road surface.

\section{The dynamic model of an automobile}

For the analysis a model for simulating the automobile behavior was developed based on a three dimensional automobile model, shown in Fig 1. In the simulation the automobile responses such as deceleration of the automobile, stopping distance after braking and vertical load of the tire can be calculated, provided the automobile initial speed, the longitudinal road profile are given as inputs.

The system of equations of a three dimensional model of the automobile may be written as follows:

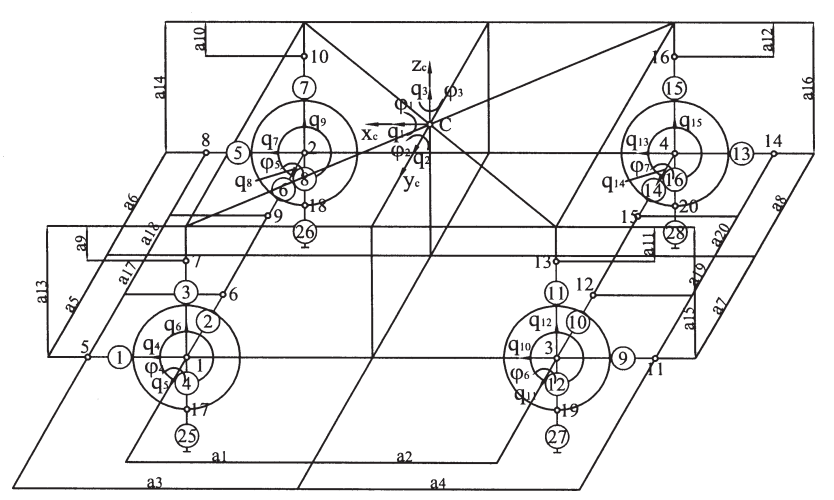

a)
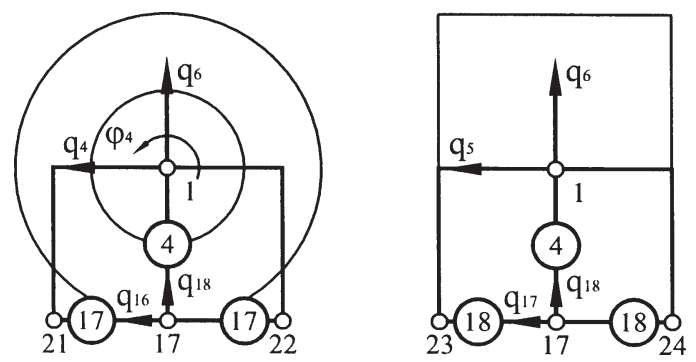

b)

Fig 1. Vehicle model and symbol notation: $\mathrm{a}$ - a three dimensional model; $\mathrm{b}$ - a tyre model

$$
[M]\{\ddot{q}\}+[C]\{\dot{q}\}+[K]\{q\}=\{F(t, q, \dot{q})\},
$$

where $[M],[C],[K]$ are mass, damping and stiffness matrices, respectively; $\{F(t, q, \dot{q})\}$ is a nonlinear load vector; $\{q\},\{\dot{q}\},\{\ddot{q}\}$ are displacement, velocity and acceleration vectors, respectively.

The dynamic model of the braking system includes a brake rotor, housing, piston, pads, hydraulic cylinder, wheel and part of the suspension (Fig 2).

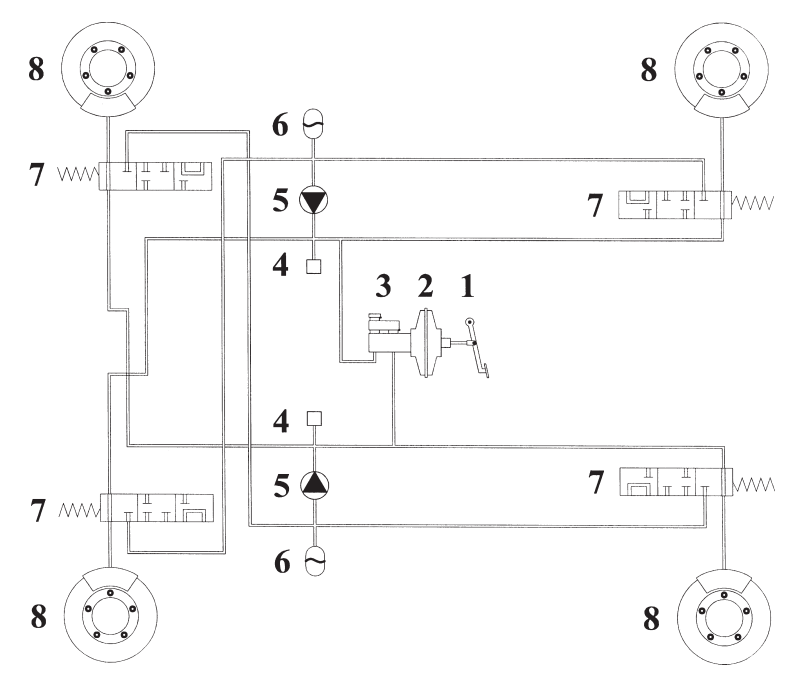

Fig 2. Principal scheme of a hydraulic brake system:

1 - braking pedal; 2 - booster; 3 - main cylinder;

4 -dampfer; 5 - pump; 6 - hydraulic accumulator;

7 - electromagnetic solenoid valve; 8 - disk brake mechanism

In this article a vehicle hydraulic break system consisting of two contours is considered. The main components of the system are shown in Fig 2. When the driver presses a brake pedal, it pushes down the piston in master cylinder 1, creating pressure in the fluid in pipeline 2. An ideal variant is when the fluid is incompressible, but in a real model it is not so. The fluid comes to hydraulic amplifier 3 , where the pressure grows up propotionally to the cross sections of pistons. Two contour separator 4 is intended to preventthe failure of all the system when one of the cylinders or pipelines does not work properly. When one countour looses its function, the other continues to brake. This requirement is essential for all brake systems [1-3]. During braking the pressure of the fluid is transmitted to wheel cylinders 5-8, which press the brake pads against the revolving disc. Amplifier 3 and the difference in cross section of the cylinders allow to apply a relatively small force on the pedal to get a large force on the brake pads.

The movement of the fluid in the hydraulic pipeline is accepted as one dimensional and unsteady, i.e. all local speeds are considered to be equal to the average speed and dependent on time. The pressure also 
is considered identical at all points of the cross section and dependent on longitudinal coordinate of the pipeline and time. Such movement of the fluid is characterized by the occurrence of a wave of increasing and lowering pressure, which runs with the velocity of sound, starting either from the place of the pressure change or from the place of the deformation of the pipeline walls [4-6]. Equation of the fluid continuity can be written in a differential form as follows:

$$
\frac{\partial}{\partial t}[S(x) \rho]+\frac{\partial}{\partial x}[S(x) \rho v]=F_{1}(x),
$$

where $\rho, v$ are density and velocity of fluid, $S(x)$ is cross section area of the pipeline, $F_{1}(x)$ is discharge of fluid mass to the unit of the length, in the pipeline.

Equation of fluid flow impulse (momentum) is:

$$
\begin{aligned}
& \frac{\partial}{\partial t}[S(x) \rho v]+\frac{\partial}{\partial x}\left[S(x)\left(p+\rho v^{2}\right)\right]+ \\
& \Pi(x) \tau+S(x) \rho a_{x}=F_{2}(x)+p \frac{\partial S}{\partial x},
\end{aligned}
$$

where $p$ is fluid pressure, $\Pi(x)$ is perimeter of cross section of the pipeline, $\tau$ is tangential fluid stress in the inner surface of the pipeline, $a_{x}$ is acceleration along $x$ axis, $F_{2}(x)$ is kinetic energy of the fluid flow in the pipeline to the unit of area.

The system of equations (2) and (3) can be written as the system second-order quasi-linear differential equations:

$$
[A]\left\{\frac{\partial u}{\partial t}\right\}+[B]\left\{\frac{\partial u}{\partial x}\right\}=\{f\},
$$

where $a_{i j}, b_{i j}, f_{i}$ are matrices $[A],[B]$ and vector $\{f\}$ elements which depend on $t, x$ and elements $u_{i}$ of vector $\{u\}$.

The dynamic model of the braking system includes a brake rotor, housing, piston, pads, hydraulic cylinder, wheel and part of the suspension (Fig 3). The system of equations of the caliper disk brake may be written as follows:

$$
\begin{aligned}
& m_{b 1} \ddot{q}_{b 1}=-p_{1} S_{1}-k_{b 3}\left(q_{b 1}+q_{b 4}\right)-c_{b 3}\left(\dot{q}_{b 1}+\dot{q}_{b 4}\right)- \\
& F_{f r 12} \operatorname{sign}\left(\dot{q}_{b 1}-\dot{q}_{b 2}\right)-F_{f r 14} \operatorname{sign}\left(\dot{q}_{b 1}+\dot{q}_{b 4}\right) ; \\
& m_{b 2} \ddot{q}_{b 2}=p_{1} S_{1}-F_{f r 12} \operatorname{sign}\left(\dot{q}_{b 2}-\dot{q}_{b 1}\right)-F_{N 1} ; \\
& F_{N 1}=\left\{\begin{array}{l}
0, q_{b 3} \leq \Delta_{1} \\
k_{b 1}\left(q_{b 2}-\left(q_{b 3}-\Delta_{1}\right)\right)+ \\
c_{b 1}\left(\dot{q}_{b 2}-\dot{q}_{b 3}\right), q_{b 3}>\Delta_{1}
\end{array} ;\right. \\
& m_{b 3} \ddot{q}_{b 4}=-k_{b 3}\left(q_{b 4}+q_{b 1}\right)-c_{b 3}\left(\dot{q}_{b 4}+\dot{q}_{b 1}\right)-
\end{aligned}
$$

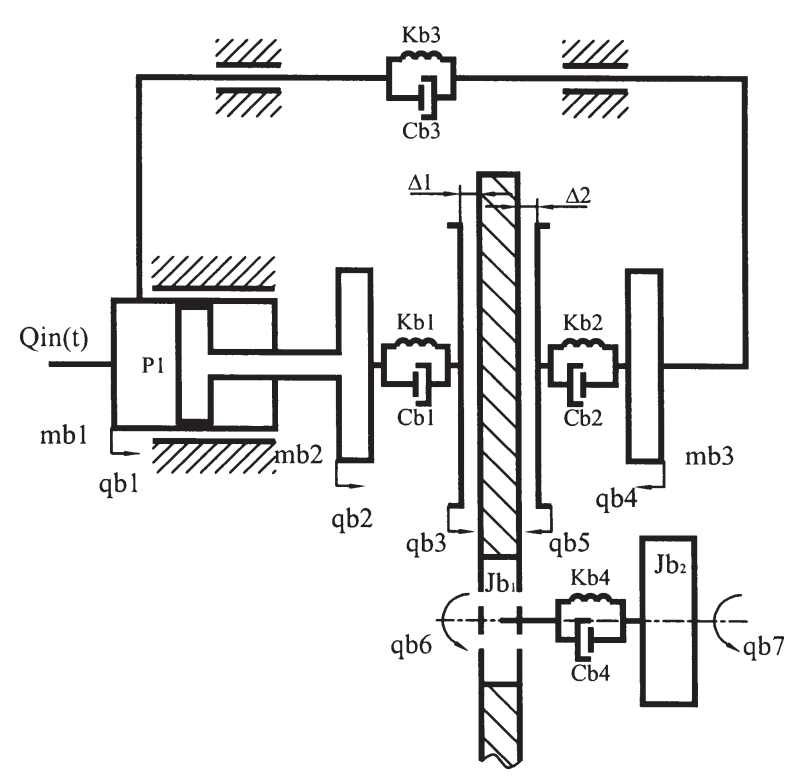

Fig 3. The main scheme of the braking system

$$
\begin{aligned}
& F_{N 2}-F_{f r 14} \operatorname{sign}\left(\dot{q}_{b 1}+\dot{q}_{b 4}\right) ; \\
& F_{N 2}=\left\{\begin{array}{c}
0, q_{b 5} \leq \Delta_{2} \\
k_{b 2}\left(q_{b 4}-\left(q_{b 5}-\Delta_{2}\right)\right)+c_{b 2}\left(\dot{q}_{b 4}-\dot{q}_{b 5}\right), q_{b 5}>\Delta_{2}
\end{array}\right. \\
& \dot{p}_{1}=\frac{K(p)}{V_{0}+S\left(q_{b 2}-q_{b 1}\right)}\left(Q_{i n}-S\left(\dot{q}_{b 2}-\dot{q}_{b 1}\right)\right) ; \\
& J_{b 1} \ddot{q}_{b 6}=-M_{b} \operatorname{sign}\left(\dot{q}_{b 6}\right)- \\
& k_{b 4}\left(q_{b 6}-q_{b 7}\right)-c_{b 4}\left(\dot{q}_{b 6}-\dot{q}_{b 7}\right) ; \\
& M_{b}=R_{a}\left(F_{N 1}+F_{N 2}\right) f
\end{aligned}
$$

where $m_{b 1}$ is the mass of a hydraulic cylinder; $m_{b 2}, m_{b 3}$ are masses of pads; $J_{b 1}, J_{b 2}$ are inertia mass moments of disk and tire; $k_{b 1}, k_{b 2}$ and $c_{b 1}, c_{b 2}$ are stiffness and damping coefficients of inner pads, respectively; $k_{b 3}, c_{b 3}$ are stiffness and damping coefficients of housing; $\Delta_{1}, \Delta_{2}$ are initial gaps between a pad and a disk; $Q(t)$ is discharge of fluid; $F_{f r 12}$ is friction force between a cylinder and a piston; $F_{f r 14}$ is friction force between a cylinder and a pad; $F_{N 1}, F_{N 2}$ are normal forces between pads and the disk; $S$ is a cross-section area of the piston; $V_{0}$ is initial volume of the cylinder; $M_{b}$ is a brake torque; $R_{a}$ is an average radius; $f$ is friction coefficient between pad and disk; $q_{b 1}, q_{b 2}, \ldots, q_{b 7}$ are generalized coordinates.

The tire friction force depends on the vertical force, longitudinal tire slip $(\lambda)$, velocity $(v)$ and slip angel $(\alpha)$ and is: 


$$
F_{T}=F_{N} \mu(\lambda, v, \alpha),
$$

where $F_{N}$ is a vertical (normal) force.

The coefficient of friction between the tire and the road is:

$$
\mu(\lambda, v, \alpha)=\exp \left(b_{1} v\right) \cdot \exp \left(b_{2} \alpha\right) \cdot \sum_{i=0}^{n} a_{i} \lambda^{i}
$$

where $b_{i}$ and $a_{i}$ are known coefficients. The function $\mu(\lambda, v, \alpha)$ is shown in Fig 4. It is evident that the peak of the friction coefficient varies between 0.10 and 0.20 .

The road surface roughness is periodic with period $L_{0}$ and is modeled as a stochastic process and periodic in space:

$$
\begin{aligned}
& z(x)=z_{0}(x)+\sum_{k=1}^{N}\left(A_{k}\left(\sin \left(\omega_{k} x\right)+\cos \left(\omega_{k} x\right)\right)\right), \\
& z_{0}(x)=A_{0} \sin \left(\frac{2 \pi}{L_{0}} x\right)
\end{aligned}
$$

where $A_{k}, \omega_{k}$ are independent normal random variables with known means and standard deviations.

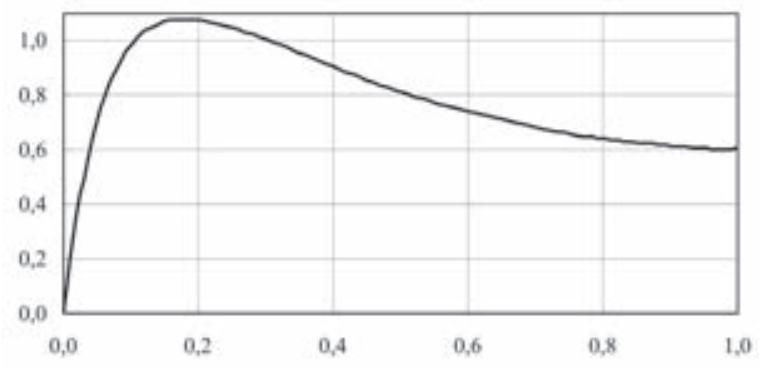

Fig 4. Friction coefficient curve

\section{Representation of results}

As an example of the vehicle (Rover 620i, 1995) braking the process is studied when the vehicle moves on the asphalt concrete pavement, an initial speed is equal to $v=40 \mathrm{~km} / \mathrm{h}$ and $v=50 \mathrm{~km} / \mathrm{h}$.

The period of roughness changes from $0.10 \mathrm{~m}$ to $2.0 \mathrm{~m}$ and amplitude is $A_{0}=30 \mathrm{~mm}$. The force acting on the braking pedal is $2.1 \mathrm{kN}$ (Fig 5).

The coefficients of friction between the tire and the dry asphalt surface of road are:

$$
\begin{aligned}
& a_{0}=0.00844566 ; a_{1}=21.0936 ; a_{2}=-177.457 ; \\
& a_{3}=865.722 ; a_{4}=-2741.71 ; a_{5}=5691.7 ; \\
& a_{6}=-7627.01 ; a_{7}=6327.81 ; a_{8}=-2948.7 ; \\
& a_{9}=589.146
\end{aligned}
$$

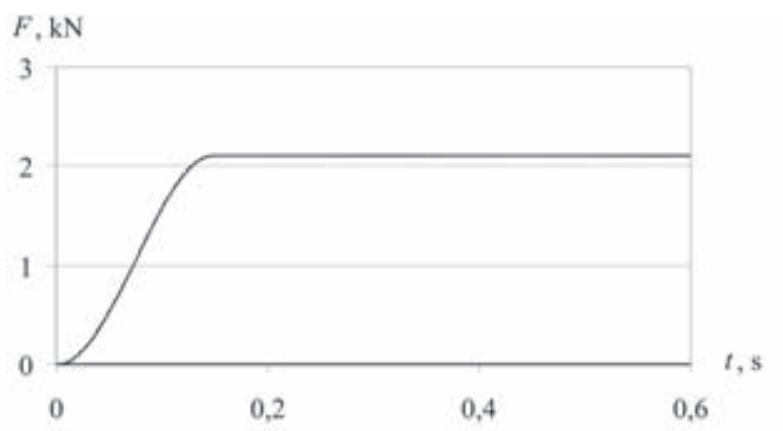

Fig 5. Time diagrams of the force acting on the braking pedal

Time diagrams of friction coefficient $\mu(t)$ of the front axle tire at different roughness periods $L_{0}$ are shown in Fig 6.

Time diagrams of normal force of tire of front axle with different roughness period $L_{0}$ are shown in Fig 7.

The dependences of the vehicle braking distance $L_{b}$ on period of roughness at different initial braking velocities are shown in Fig 8.

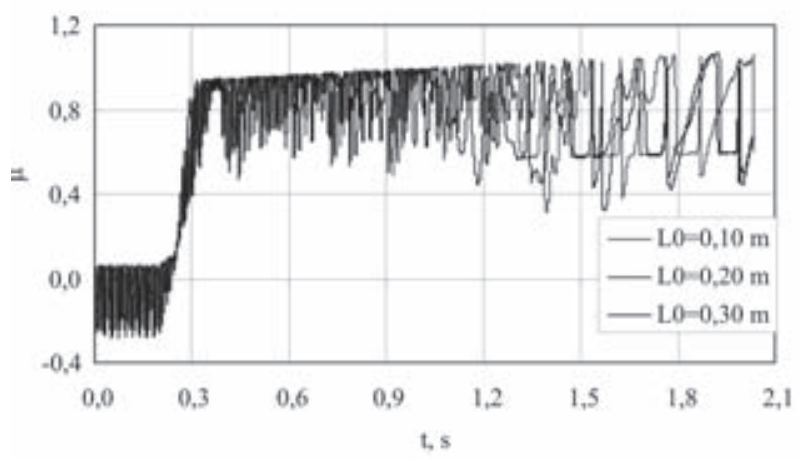

Fig 6. Time diagrams of a friction coefficient with different period of roughness $L_{0}$ when initial velocity of vehicle braking is $v=50 \mathrm{~km} / \mathrm{h}$, contact patch of tire and road surface is $L_{\mathrm{c}}=0.20 \mathrm{~m}$

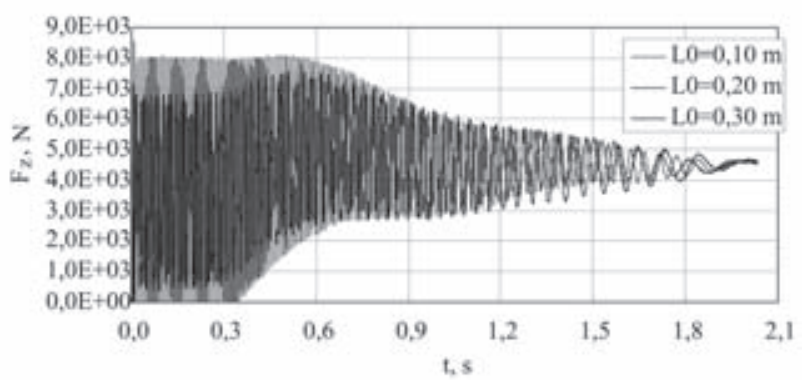

Fig 7. Time diagrams of normal force of tire of front axle at different periods of roughness $L_{0}$ when initial velocity of vehicle braking is $v=50 \mathrm{~km} / \mathrm{h}$, contact patch of tire and road surface is $L_{\mathrm{c}}=0.20 \mathrm{~m}$ 


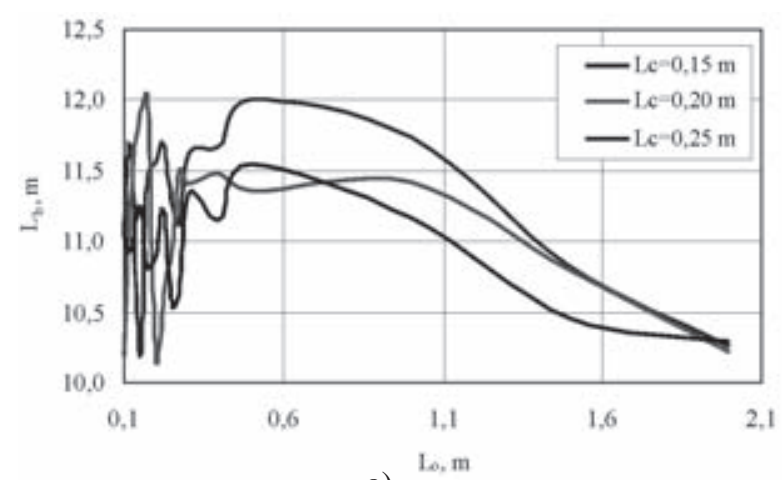

a)

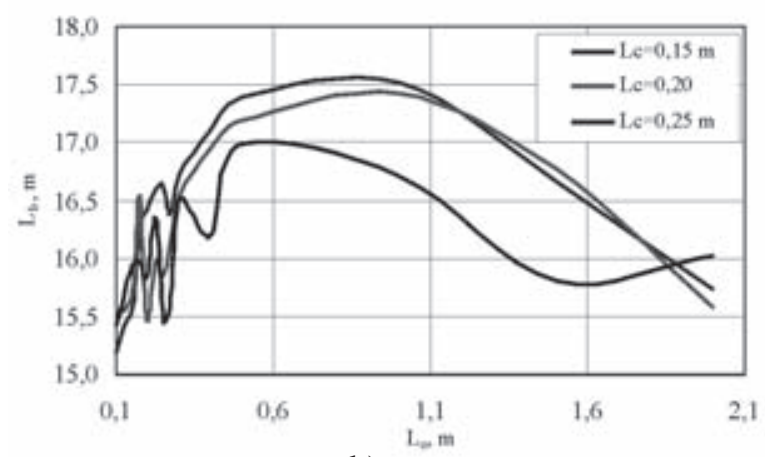

b)

Fig 8. Dependencies of braking distance $L_{b}$ from period of roughness $L_{0}$ when contact length of tire and road surface is $L_{C}=0.20 \mathrm{~m}: \mathrm{a}-v=40 \mathrm{~km} / \mathrm{h}$ $\mathrm{b}-v=50 \mathrm{~km} / \mathrm{h}$

\section{Conclusions}

1. Braking distances of the vehicle (Rover 620i, 1995) with hydraulic ABS on the surface with short wave roughness are obtained. The braking distance is about 2 metres longer when initial braking velocity is $40 \mathrm{~km} / \mathrm{h}$ and about 2.5 metres longer when initial braking velocity is $50 \mathrm{~km} / \mathrm{h}$, as compared with a minimum braking distance.

2. A mathematical model of the vehicle with a hydraulic brake system with ABS is developed. Proper work of the hydraulic brake system with such components as hydraulic amplifier, two contour separator and electromagnetic valve shows the possibility to add more complicated components. The developed model allows to investigate any failure of a hydraulic brake system by changing the boundary conditions (fluid pressure at any point of pipelines, motion of pistons, air quantity and etc.) and to simulate the behavior of the vehicle on the road.

3. By using the mathematical model of a vehicle it is possible to analyze the vehicle braking process with different characteristics of road surface and different vehicle parameters.

\section{References}

1. Bogdevičius, M.; Vladimirov, O. Simulation of automobile hydraulic brake system. Mechanika, Nr. 3 (35). Kaunas: Technologija, 2002, p. 67-70.

2. Bogdevičius, M.; Vladimirov, O. Dynamic processes in the hydraulic braking system of transport vehicle. In: The Fourth International Conference „Heavy Machinery HM 2002“, Kraljevo, 28-30 June 2002 : proceedings / Faculty of Mechanical Engineering, University of Kragujevac. Kraljevo: Riza, 2002, p. 37-40. ISBN 8682631-15-6.

3. Bogdevičius, M.; Vladimirov, O. Investigation of dynamic processes in the hydraulic braking system of transport vehicle with anti-lock brake system. Transport and Telecommunication, Vol 5, No 1, 2004, p. 85-90.

4. Bogdevičius, M. Simulation of dynamic processes in hydraulic, pneumatic and mechanical drivers and their elements. Vilnius: Technika, 2000. 96 p.

5. Aladjev, V.; Bogdevičius, M. Maple 6: solution of the mathematical, statistical and engineering - physical problems (Maple 6: решение математических, статистических и инженерно-физических задач). Moscow: Laboratory of Basic Knolegdes, 2001. 864 p. (in Russian).

6. Aladjev, V.; Bogdevičius, M.; Prentkovskis, O. New software for mathematical package Maple of releases 6,7 and 8. Monograph. Vilnius: Technika, 2002. 404 p. 